\title{
Performance Evaluation of an Air-Conditioning Compressor Part I: Measurement and Design Modeling*
}

\author{
THOMAS W. BEIN and YU-TAI LEE ${ }^{\dagger}$
}

David Taylor Model Basin, 9500 MacArthur Blvd., West Bethesda, MD 20817-5700, USA

(Received 12 May 1998; In final form 10 July 1998)

\begin{abstract}
In order to comply with legislation to eliminate the use of refrigerants that damage the ozone layer, it is necessary to redesign centrifugal compressors, used by the US Navy for shipboard air-conditioning systems, to use an environmentally acceptable refrigerant. This paper describes an evaluation of a 125-ton compressor designed to use HCFC-124 as the refrigerant. The objectives are not only conducting the performance evaluation, but also pinpointing the design problems for achieving a high-performance compressor. The design method used to design the 125-ton compressor is first reviewed and some related performance curves are predicted based on a quasi-3D method. In addition to an overall performance measurement, a series of instruments were installed on the compressor to identify where the measured performance differs from the predicted performance. The measurement techniques for providing the diagnostic flow parameters are also described briefly. Part II of this paper provides predictions of flow details in the areas of the compressor where there were differences between the measured and predicted performance.
\end{abstract}

Keywords: Air-conditioning, Centrifugal compressor, Vaneless diffuser, Volute, Cutwater, Performance

\section{INTRODUCTION}

US Navy shipboard centrifugal chilled water airconditioning plants currently utilize refrigerant CFC-114. In response to the world community decision to eliminate the use of $\mathrm{CFC}$ refrigerants, the US Navy has begun a program to convert the air-conditioning plants to an environmentally acceptable refrigerant. HCFC-124 was identified as a potential candidate to replace the $\mathrm{CFC}-114$.
A contract was competitively awarded to design and build a high efficiency HCFC-124 compressor for use on a 125 -ton cooling capacity air-conditioning plant. The Annapolis Detachment of the Carderock Division Naval Surface Warfare Center evaluated the performance of the centrifugal compressor.

Before high-speed computer workstations were available, centrifugal compressors were designed using dimensionless scaling techniques. Currently, a variety of computational models are available

\footnotetext{
* This paper was originally presented at ISROMAC-7.

${ }^{\dagger}$ Corresponding author. Tel.: 301227 1328. Fax: 301227 5707. E-mail: ylee@dt.navy.mil.
} 
to predict the performance of a centrifugal compressor. These can be divided into two groups: design models and analysis models. Design models are used to establish the dimensions of the physical hardware. They are orders of magnitude faster than analysis models because they utilize builtin empirical data to permit simplification of the models of the fluid flow field. The only flow details available are the flow parameters entering and exiting a particular component. The time and effort required to reach a solution are fast enough to allow the designer to evaluate the impact of hundreds of different geometric combinations. Analysis models provide precise details of the behavior of the flow, but require extensive computational resources to reach a solution. Hundreds of man hours are required to prepare a geometric model of a centrifugal compressor. Seemingly insignificant discontinuities in the geometry, such as the transition from one part to another, can cause erroneous results. Only highly qualified and experienced fluid dynamists can produce solutions with confidence.

The effort reported herein documents the final design configuration, the predicted performance and the experimental performance of the 125-ton HCFC-124 compressor. In addition, a series of modifications were made to the compressor in an effort to investigate the difference between the measured performance and the design predicted performance. The details of the modifications and the test results are presented. The second part of this paper will present comparison results on the volute from an analysis model using Computational Fluid Dynamics (CFD).

\section{DESIGN MODEL}

The new HCFC-124 compressor was parametrically designed using a commercially available computer program (NREC Report, 1995a). The preliminary design program computes the gas properties of HCFC-124 from the Martin Hou equation of state. The design prediction is based on an ideal velocity vector analysis with losses added based on empirical data. The output produced by the program tabulates the results for the major components so that the performance of the individual components can be evaluated.

The detailed design of the compressor was also performed with a commercially available fluid dynamic program (NREC Report, 1995b). The detailed design program predicts loading on the blades from the preliminary design results and also generates the blade profiles. The analysis of the impeller consists of a two-dimensional streamline curvature analysis in the meridional plane followed by a blade-to-blade analysis that is based on conservation of vorticity. A second blade-to-blade analysis is also provided, for use at the end of the design process, that utilizes a more accurate but more time consuming, finite difference blade-to-blade analysis.

Most of the compressor was commercially fabricated using traditional methods. The impeller was machined by a 5-axis Numerically Controlled (NC) Milling Machine. This approach was used to ensure that the blade profile accurately reproduced the geometry defined by the detailed design program. The software used to control the NC machine translated the ruled surface blade definitions into machine motion. The impeller shroud was brazed onto the impeller.

\section{EXPERIMENTAL SETUP}

The Centrifugal Compressor Development Facility (CCDF) at the Annapolis Laboratory of the Naval Surface Warfare Center was utilized to measure the performance of the compressor. The CCDF was designed for a cooling capacity of 12.5 to 500 tons. A schematic of the CCDF is shown in Fig. 1. Gas entering the compressor passes through the suction pipe where the total temperature and static pressure are measured. Leaving the compressor, the gas passes into the discharge pipe where the total temperature and static pressure are measured. The gas flowrate is then measured by a nozzle-flow meter, an orifice-flow meter, and a turbine-flow meter. 


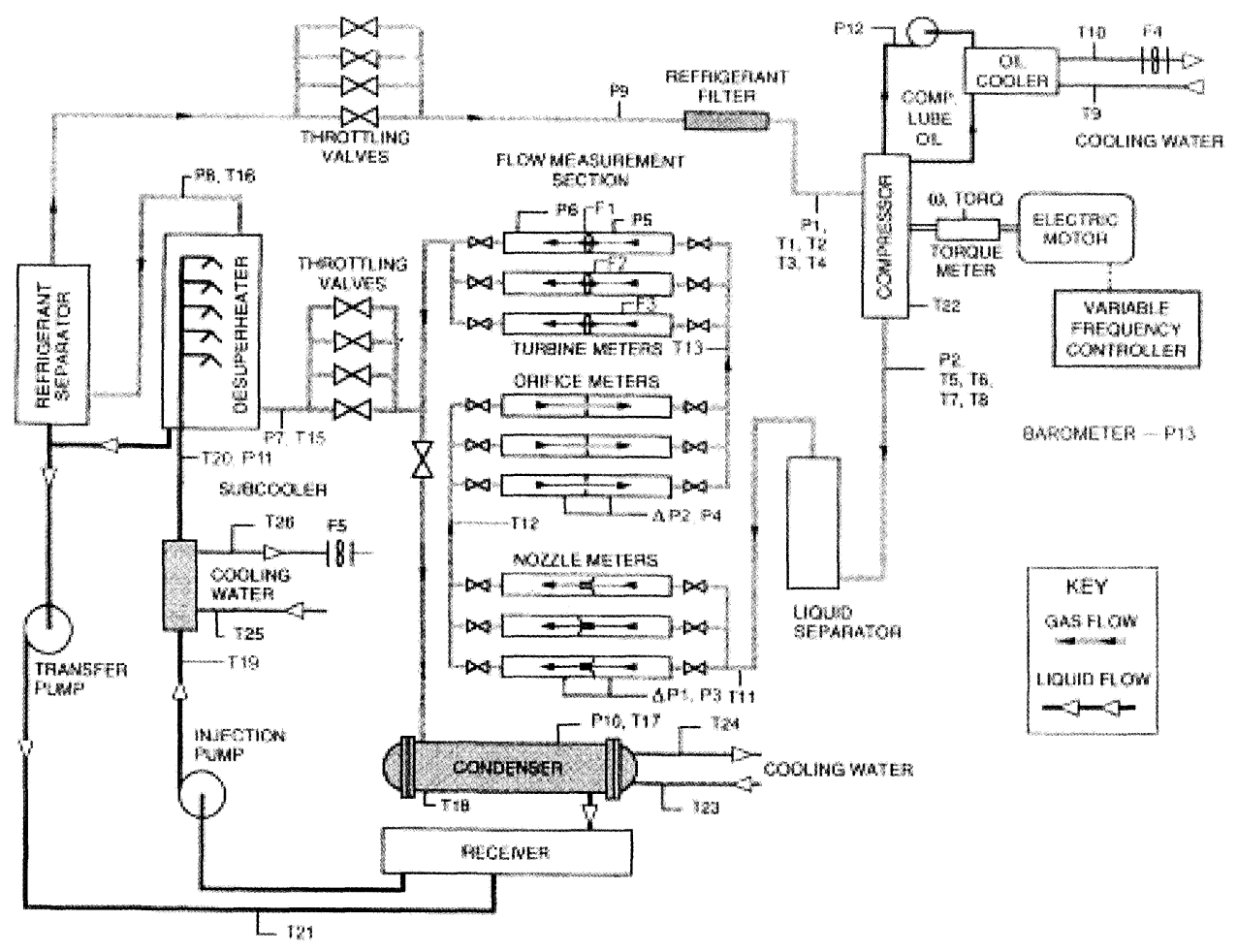

FIGURE 1 Centrifugal compressor development facility refrigerant loop schematic.

To improve the measurement accuracy of each flowmeter type, different sizes of flow meters with overlapping ranges are installed. The gas stream is split into flow to the condenser and flow to the desuperheater. The gas flow that enters the desuperheater is cooled by liquid refrigerant pumped from the condenser through a series of spray nozzles. The spray nozzles atomize the pressurized liquid refrigerant to create a fine mist of liquid droplets inside the desuperheater. These liquid droplets are vaporized into their gaseous state by absorbing heat from the discharge gas, thus decreasing the gas stream temperature to the desired compressor inlet temperature. Any liquid refrigerant carried by the gas stream out of the desuperheater is removed by the refrigerant separator. Four different size throttling valves are used to regulate the pressure and mass flow rate returning to the compressor inlet. The gas stream diverted just after the flow measurement section is cooled to its liquid state in the condenser. The condenser is cooled by either river water or by an auxiliary chilled water cooling unit. The liquid refrigerant is stored in the receiver, and used to supply liquid refrigerant to cool the hot discharge gas in the desuperheater.

The compressor is driven by a $500 \mathrm{HP}, 3600 \mathrm{rpm}$ at $60 \mathrm{~Hz}$, electric motor which is mounted on a rigid base. Power to the motor is supplied through a variable frequency controller. The controller output frequency is varied from 0 to $120 \mathrm{~Hz}$ that results in a motor operating range of 0 to $7200 \mathrm{rpm}$. A gearbox with hydrodynamic journal and thrust bearings is used to achieve the required impeller speed. A torque meter is installed between the motor and the compressor gearbox to measure compressor input power and rotational speed. The oil lubrication system for the compressor is also attached to the rigid mounting base. The oil cooler, used during compressor operation, was designed to remove heat from the lubrication system. The heat rejected into the water passing through the oil 
cooler was measured to quantify the compressor friction loss.

\section{COMPRESSOR DESCRIPTION}

The cross section view of the compressor is shown in Fig. 2. The design incorporated two rows of inlet guide vanes, which are also shown in the figure. The inlet guide vanes were configured so that the upstream set of vanes rotated one-half the amount of the downstream set. The intent was to improve the control of the flow angle entering the impeller. The shrouded impeller has 13 main blades and 13 splitter blades with a $30^{\circ}$ backswept. The impeller exit radius is 4.02 in $(102.11 \mathrm{~mm})$. The radius ratio of the vaneless diffuser exit to the impeller exit is 1.52. The inlet width of the vaneless diffuser is $0.35 \mathrm{in}(8.89 \mathrm{~mm})$ and the exit width is $0.1425 \mathrm{in}$ $(3.62 \mathrm{~mm})$. The design point for the compressor was a condensing water inlet temperature of $88^{\circ} \mathrm{F}$, and a chilled water outlet temperature of $44^{\circ} \mathrm{F}$. At the design point, the impeller has a rotating speed of $17,983 \mathrm{rpm}$, the impeller tip speed is $630 \mathrm{fps}$ $(192 \mathrm{~m} / \mathrm{s})$, the flow coefficient is 0.0654 and the head coefficient is 1.2324 . The circumferential Mach number at the design point was 1.495 . The predicted

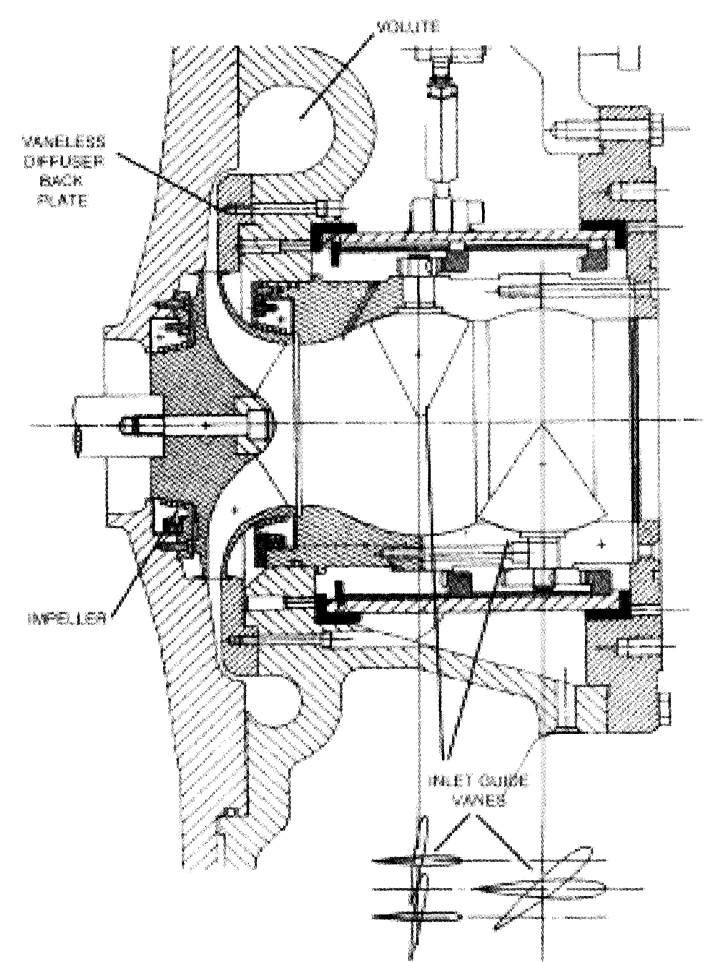

FIGURE 2 Cross section view of the tested 125-ton HCFC124 compressor.

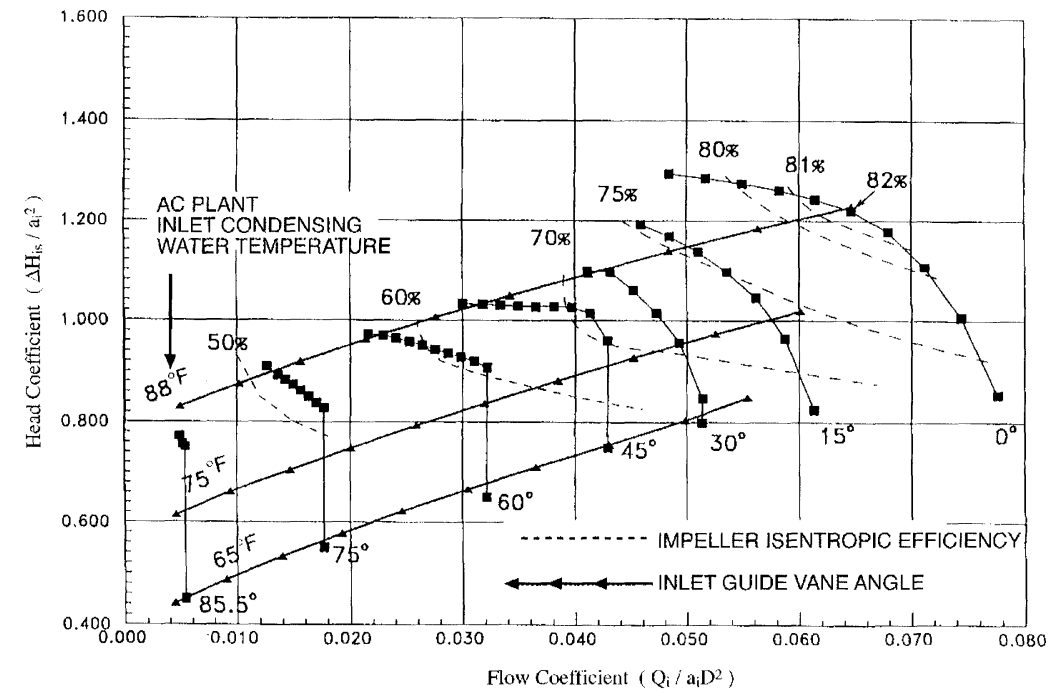

FIGURE 3 Predicted compressor performance at $\mathrm{M}=1.495$. 
compressor performance is shown in Fig. 3. The 125-ton AC plant characteristics for three inlet condensing water temperatures, $88^{\circ} \mathrm{F}, 75^{\circ} \mathrm{F}$ and $65^{\circ} \mathrm{F}$, are also plotted. The maximum impeller isentropic efficiency predicted was $82 \%$.

\section{COMPRESSOR PERFORMANCE}

The details of many measured and derived quantities are summarized in Bein and Lee (1998). The measured performance of the compressor is shown in Figs. 4-6. The design Mach number was 1.495. Figure 4 indicates that the measured performance did not reach the design head condition. The

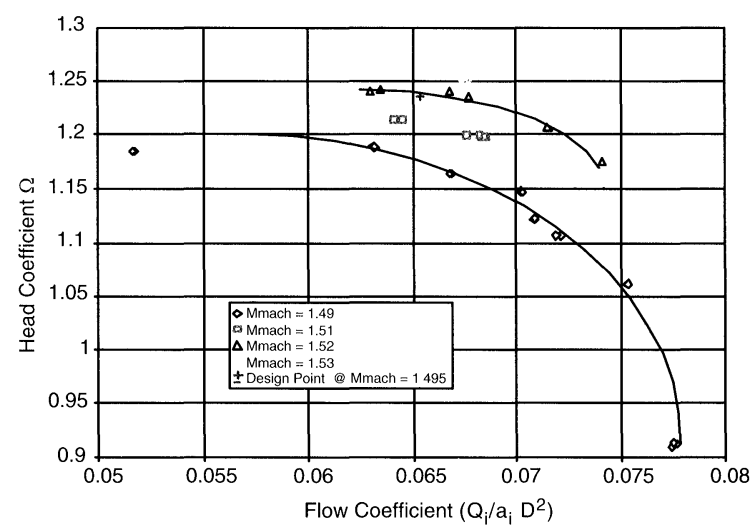

FIGURE 4 Non-dimensional head coefficient versus flow coefficient at various Mach numbers.

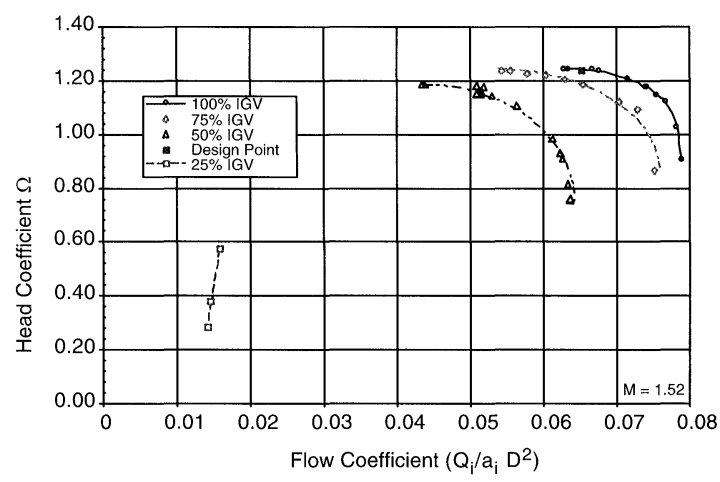

FIGURE 5 Non-dimensional head coefficient versus flow coefficient at various inlet guide vane positions.

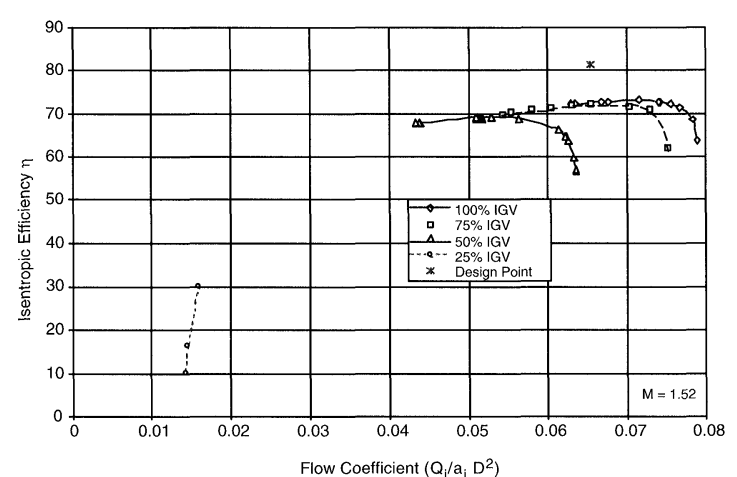

FIGURE 6 Isentropic efficiency versus flow coefficient at various inlet guide vane positions.

required head condition was achieved when the impeller speed was increased to $18,850 \mathrm{rpm}$ that increased the Mach number to 1.52. At the higher Mach number, the compressor was able to reach the design head condition. The isentropic efficiency, however, was approximately $10 \%$ below the prediction as shown in Fig. 6.

\section{PRESSURE LOSSES FROM COMPRESSOR COMPONENTS}

Since the large discrepancy of the predicted and measured overall efficiencies, fifteen static pressure taps were initially installed in the compressor nonrotating components to provide analysis of the performance of the impeller, the diffuser, the volute and the exit discharge diffuser. The measured static pressure differences across each component are shown in Table I. It also shows the predicted results from the compressor design program. Modifications to the simulation parameters were also investigated to improve the fit to the experimental data. It was possible to reduce the difference between the predicted and the measured results for all of the components except at the compressor discharge where the measured pressure was lower than the predicted. This indicates that in the volute there were losses that were not accounted for in the compressor design program or severe flow separations occurred there. 
TABLE I Comparison of measured static pressures with predicted static pressures

\begin{tabular}{lcccc}
\hline Conditions & $\begin{array}{c}\mathrm{P}_{\mathrm{s}} \\
\text { at Impeller Inlet } \\
(\mathrm{psia})\end{array}$ & $\begin{array}{c}\mathrm{P}_{\mathrm{s}} \\
\text { at Impeller Outlet } \\
\text { (psia) }\end{array}$ & $\begin{array}{c}\mathrm{P}_{\mathrm{s}} \\
\text { at Vaneless Diffuser Outlet } \\
\text { (psia) }\end{array}$ & $\begin{array}{c}\mathrm{P}_{\mathrm{s}} \\
\text { at Discharge Flange } \\
\text { (psia) }\end{array}$ \\
\hline $\begin{array}{l}\text { Measured Values } \\
\begin{array}{l}\text { Prediction based on } \\
\text { Final Design Parameters } \\
\text { and actual test conditions }\end{array}\end{array}$ & 18.12 & 51.07 & 62.88 & 66.65 \\
$\begin{array}{l}\text { Reduced the shroud mean } \\
\text { Velocity ratio from 1.05 to 1.015 }\end{array}$ & 17.95 & 49.68 & 63.46 & 71.51 \\
$\begin{array}{l}\text { Increased the friction factor in } \\
\text { Vaneless Diffuser from 0.03 to 0.05 }\end{array}$ & 18.12 & 50.11 & 64.13 & 72.25 \\
\hline
\end{tabular}

Test Conditions:

Mass flow rate $=7.3 \mathrm{lbm} / \mathrm{sec}$

Shaft speed $=17,983 \mathrm{rpm}$

Circumferential mach number $=1.495$.

\section{INTERACTION OF CUTWATER AND VANELESS DIFFUSER}

Additional static pressure taps were installed to investigate the flow interaction between the vaneless diffuser and the volute cutwater (which is at $\theta=22.5^{\circ}$ ) and the flow in the volute and in the conical discharge diffuser. Total-pressure probes were installed, shown in Fig. 7, to measure the velocity field exiting the diffuser $\left(\theta=20^{\circ}\right.$ and $\theta=220^{\circ}$ ), downstream of the cutwater area $\left(\theta=40^{\circ}\right)$, and in the center of the volute $\left(\theta=250^{\circ}\right)$.

The surface finish of the vaneless diffuser front plate and the volute were polished to approximately a 64 finish to reduce the viscous losses in those components. The operating range of the modified compressor was improved due to polishing the vaneless diffuser and the volute as shown in Figs. 8 and 9 . The efficiency of the compressor, however, did not change appreciably.

Figure 10 shows the velocities measured at the vaneless diffuser exit, $\theta=220^{\circ}$, and the center of the volute, $\theta=250^{\circ}$, as viewed along the axis of the total-pressure probe. The measured velocities across the diffuser depth at the vaneless diffuser exit are significantly lower than the predicted velocity from the design model and the flow angle is about $15^{\circ}$ larger. This indicates that the actual stall margin is narrower than the design margin.

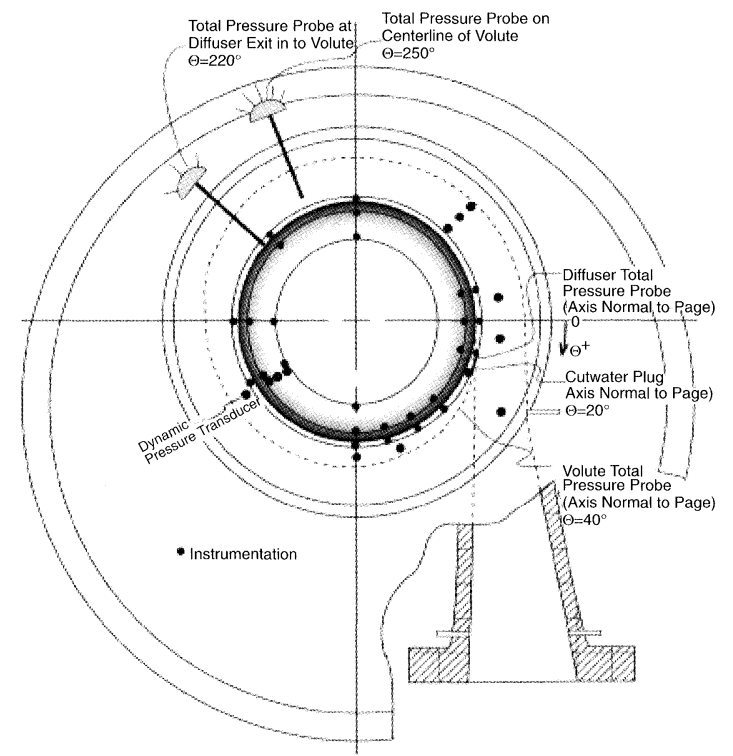

FIGURE 7 Section view (as viewed from transmission) with instrumentation.

A near $90^{\circ}$ difference in flow angle between the velocities of above and below the volute centerline indicates strong swirled vortices existed across the volute cross planes. These features invalidate the conventional volute design theory as described by Traupel (1977) and Stiefel (1972) which assume that the flow along the diffuser cross section is uniform.

In order to investigate the effect of the cutwater to the compressor performance, a cutwater plug 


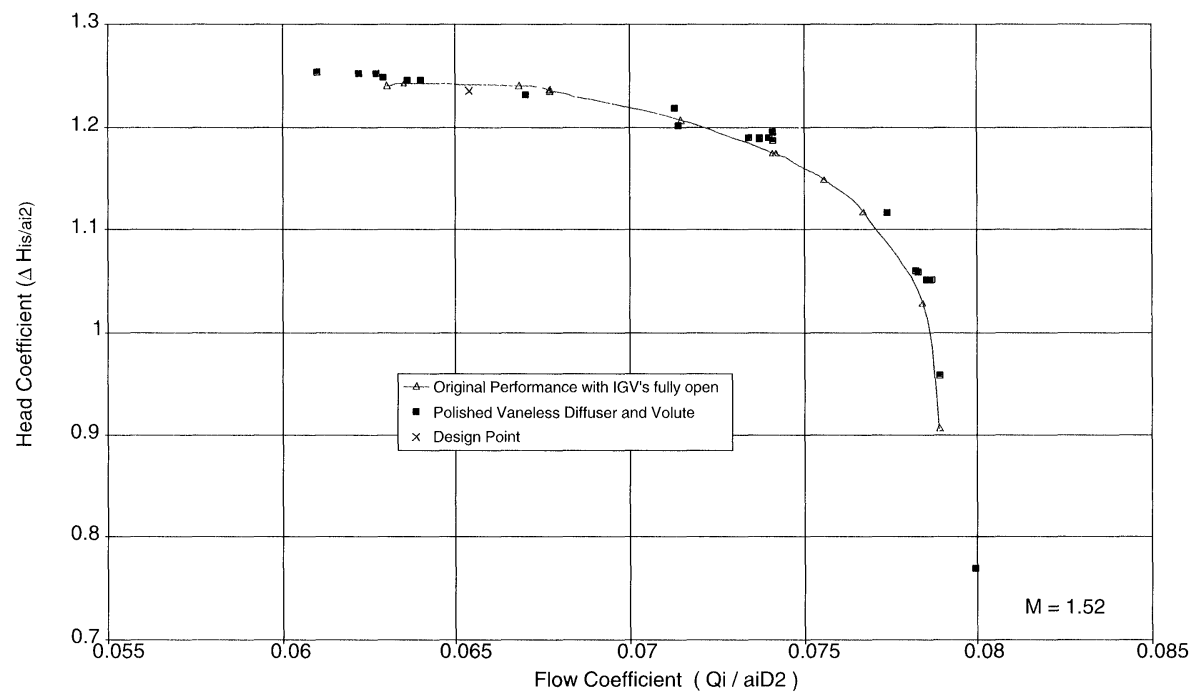

FIGURE 8 Effect of polishing vaneless diffuser and volute.

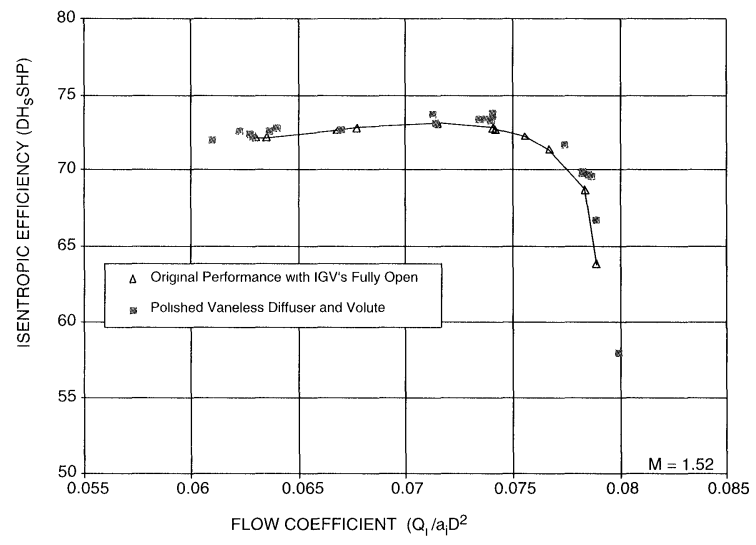

FIGURE 9 Effect of polishing vaneless diffuser and volute on the isentropic efficiency.

to open and close the cutwater opening during operation was installed. Closing the cutwater had a minimal impact on the compressor performance, approximately $0.5 \%$ drop of the impeller isentropic efficiency. The low-pressure region, at the beginning of the volute and near the cutwater region, extends upstream and affects the vaneless diffuser. This non-uniform pressure in the diffuser affects the flow exiting the impeller. The change in the static pressure between the open and closed cutwater at the exit of the vaneless diffuser is plotted in Fig. 11,

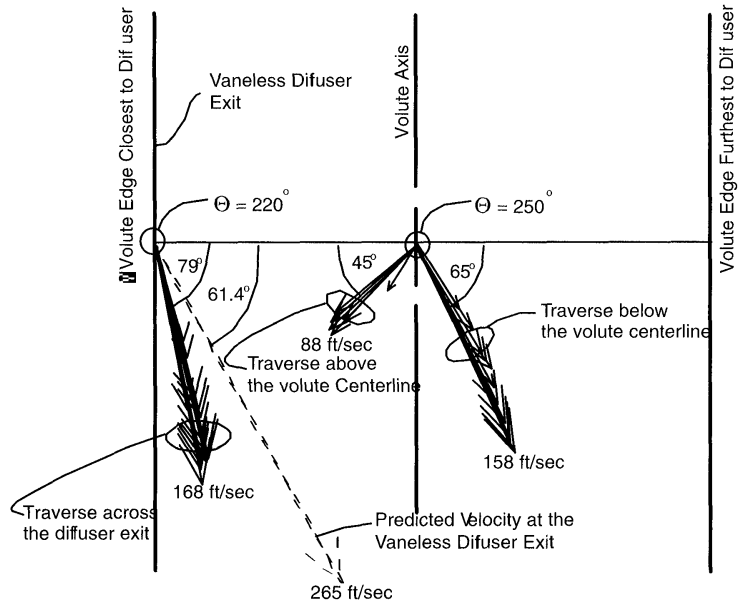

FIGURE 10 Volute velocity vectors viewed along probe axis.

where the static pressure is plotted in reference to the discharge pressure. The static pressures measured with the cutwater closed are higher than when the cutwater was open except at the point where the minimum pressure was measured.

The velocity vectors measured in the vaneless diffuser exit and the center of the volute are shown in Fig. 12. It can be seen that the velocity of fluid in the vaneless diffuser was slightly reduced when the cutwater was closed. In addition, the flow angle was 


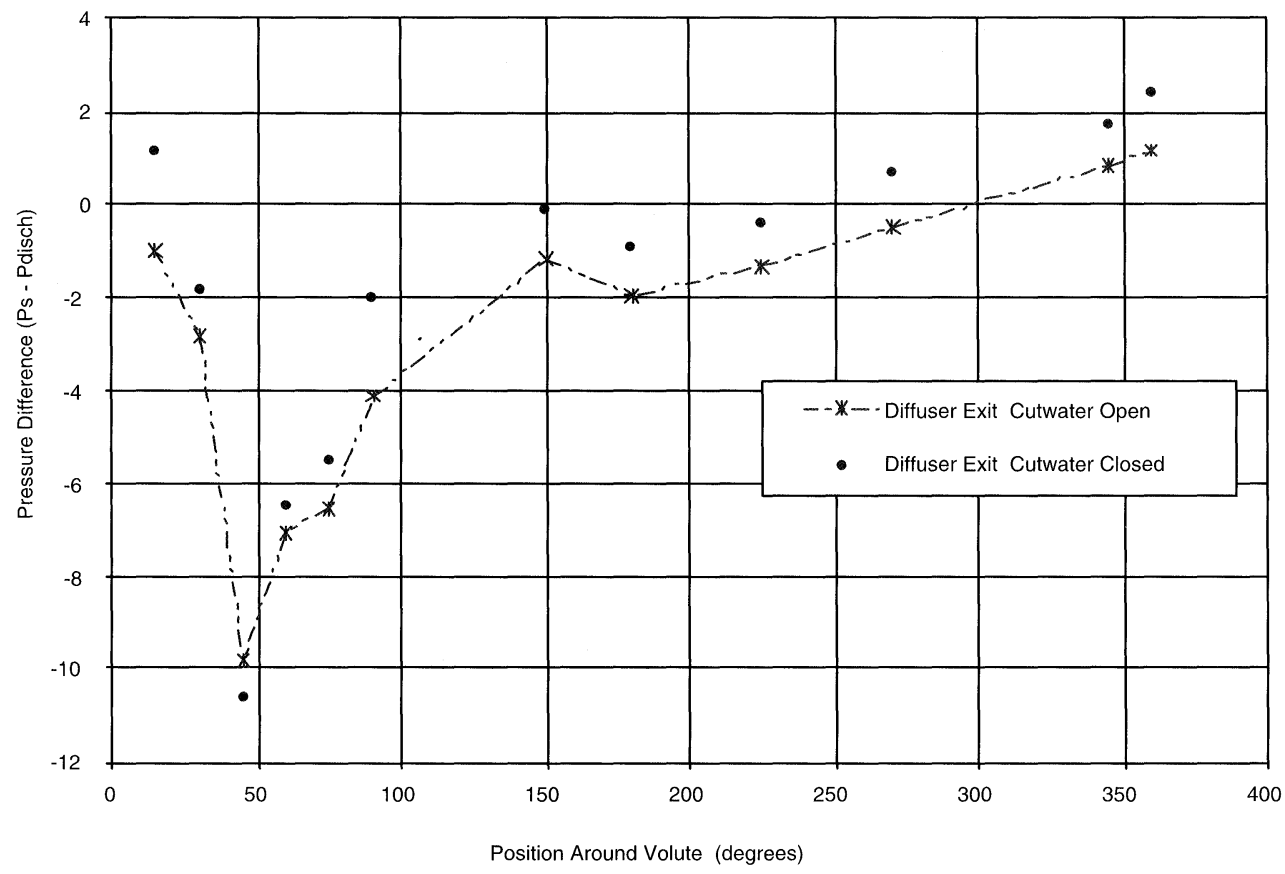

FIGURE 11 Volute wall pressure distributions with cutwater open and closed

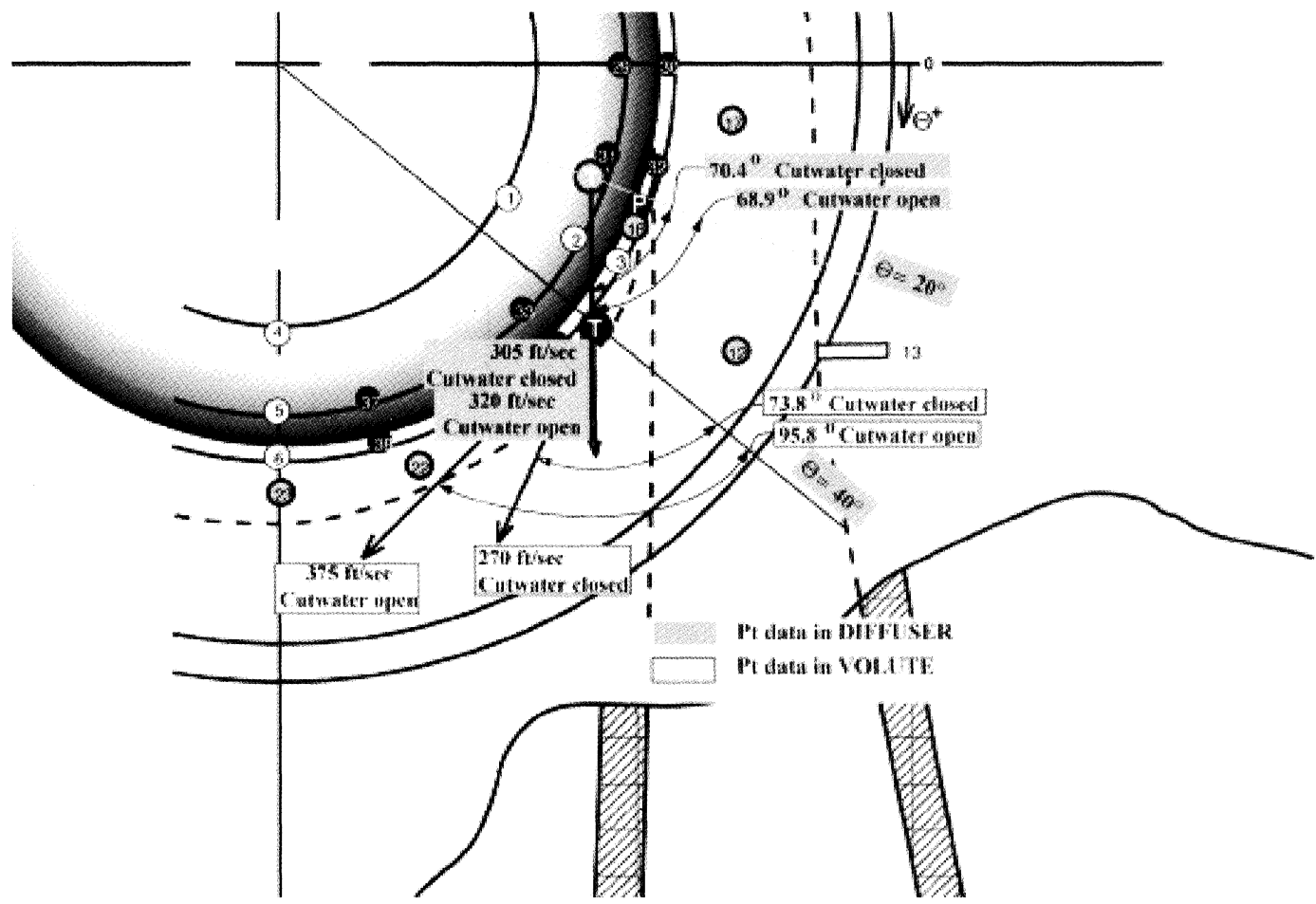

FIGURE 12 Velocity vectors in the diffuser and volute (as viewed from transmission). 
increased by a half degree. The magnitude of the velocity vector in the volute with the cutwater open was considerably higher than the vector in the vaneless diffuser. The magnitude of the velocity vector in the volute dropped by $100 \mathrm{ft} / \mathrm{s}(30.48 \mathrm{~m} / \mathrm{s})$ when the cutwater was closed. When the cutwater was closed, the velocity in the volute was lower than the velocity measured in the vaneless diffuser. The relative flow angle in the volute also changed dramatically when the cutwater was closed. When the cutwater was open, the flow in the volute was normal to a cross section plane. When the cutwater was closed, the relative flow angle in the volute was comparable to the angle measured in the vaneless diffuser.

\section{CONCLUSIONS}

Polishing the vaneless diffuser and the volute improves the operating range of the compressor. This is the result of a reduction of both the viscous drag along the surfaces and the boundary layer thickness. It, however, provides no impact on the compressor performance.

Opening and closing the cutwater at the design condition provided insight into the origin of the low pressure at the beginning of the volute. The velocity measured in the volute downstream of the cutwater dropped when the cutwater was closed. The static pressure measured in the volute downstream of the cutwater, however, was lowest with the cutwater closed. Therefore, the returning flow from the discharge diffuser passing through the open cutwater is not the cause of the low-pressure region created at the beginning of the volute by.

The low static pressure measured at the beginning of the volute has a significant negative impact on the efficiency of the compressor. Measurements showed that the low pressure measured at the beginning of the volute propagated upstream through the diffuser to the impeller. The nonuniform pressure in the volute affects the performance of the vaneless diffuser and the volute. This conclusion raises the serious concern over the applicability of the uniform-flow assumption used to design the volute.

The present study, conducted at the operating condition, indicates that adjustments can be made to the volute shape to improve the performance at a specific mass flowrate. However, compressors used for $\mathrm{A} / \mathrm{C}$ applications have a wide range of mass flowrate. Therefore, the situation remains because of the high cost to conduct a volute parametric study.

\section{Acknowledgment}

This work was sponsored by the Shipboard Energy Conservation Program administrated at the Annapolis Laboratory of the Naval Surface Warfare Center. The program manager at the Chief of Naval Operations, Code N420C, is Mr. H. Hodgkins and at the Carderock Division, Naval Surface Warfare Center, Mr. W. Stoffel.

\section{NOMENCLATURE}

a Refrigerant acoustic velocity

D Diameter of impeller

$H_{\text {is }} \quad$ Compressor isentropic enthalpy change

$m \quad$ Mass flow rate

M Mach number

$P_{\mathrm{b}} \quad$ Motor input power

$P_{\mathrm{s}} \quad$ Static pressure

$P_{\mathrm{t}} \quad$ Total pressure

$q_{\mathrm{o}, \mathrm{b}} \quad$ Heat transferred, Oil Cooler

$Q \quad$ Volume flow rate

SHP Shaft horsepower

$\eta \quad$ Isentropic efficiency $\left(\Delta H_{\text {is }} * m_{\text {avg }}\right)$

$$
\left.P_{\mathrm{b}}-q_{\mathrm{o}, \mathrm{b}}\right)
$$

$\theta \quad$ Diffuser coordinate

$\Theta \quad$ Compressor flow coefficient $\left(=Q_{i} / a_{i} D^{2}\right)$

$\Omega \quad$ Compressor head coefficient $\left(=H_{\text {is }} / a_{i}^{2}\right)$

\section{References}

Bein, T.W. and Lee, Y.T. (1998). Performance evaluation of 125-ton HCFC-124 centrifugal compressor, Naval Surface 
Warfare Center, Carderock Division, Report, CARDIVNSWC-TR-82-98/08.

NREC Report (1995a). An interactive graphics system for the performance prediction of centrifugal compressors, Report No. 1450, Northern Research and Engineering Co.

NREC Report (1995b). Detailed design of radial turbomachinery blading, Report No. 1419, Northern Research and Engineering Co.
Stiefel, W.L. (1972) Experiences in the development of radial compressors, Lecture notes for Advanced Radial Compressor course held at von Karman Institute, Brussels.

Traupel, W. (1977) Thermische Turbomaschinen, 3 ed., SpringerVerlag. 


\section{ait \\ ENERGY MATERIALS}

M A N E Y publishing

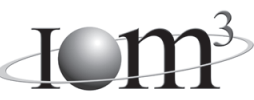

\section{Materials Science \& Engineering for Energy Systems}

Maney Publishing on behalf of the Institute of Materials, Minerals and Mining

The Institute of Materials, Minerals \& Mining

Economic and environmental factors are creating ever greater pressures for the efficient generation, transmission and use of energy. Materials developments are crucial to progress in all these areas: to innovation in design; to extending lifetime and maintenance intervals; and to successful operation in more demanding environments. Drawing together the broad community with interests in these areas, Energy Materials addresses materials needs in future energy generation, transmission, utilisation, conservation and storage. The journal covers thermal generation and gas turbines; renewable power (wind, wave, tidal, hydro, solar and geothermal); fuel cells (low and high temperature); materials issues relevant to biomass and biotechnology; nuclear power generation (fission and fusion); hydrogen generation and storage in the context of the 'hydrogen economy'; and the transmission and storage of the energy produced.

As well as publishing high-quality peer-reviewed research, Energy Materials promotes discussion of issues common to all sectors, through commissioned reviews and commentaries. The journal includes coverage of energy economics and policy, and broader social issues, since the political and legislative context influence research and investment decisions.

\section{CALL FOR PAPERS}

Contributions to the journal should be submitted online at http://ema.edmgr.com

To view the Notes for Contributors please visit: www.maney.co.uk/journals/notes/ema

Upon publication in 2006, this journal will be available via the Ingenta Connect journals service. To view free sample content online visit: www.ingentaconnect.com/content/maney

For further information please contact:

Maney Publishing UK

Tel: +44 (0)113 2497481 Fax: +44 (0)1132486983 Email: subscriptions@maney.co.uk

or

Maney Publishing North America

Tel (toll free): 8662975154 Fax: 6173546875 Email: maney@maneyusa.com

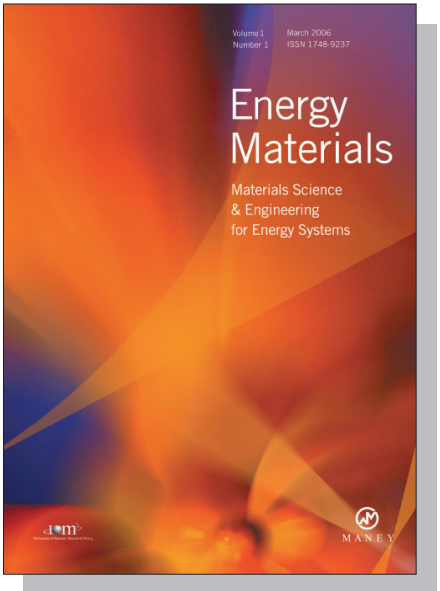

EDITORS

Dr Fujio Abe

NIMS, Japan

Dr John Hald, IPL-MPT, Technical University of Denmark, Denmark

Dr R Viswanathan, EPRI, USA

\section{SUBSCRIPTION INFORMATION}

Volume 1 (2006), 4 issues per year

Print ISSN: 1748-9237 Online ISSN: 1748-9245

Individual rate: $£ 76.00 / U S \$ 141.00$

Institutional rate: $£ 235.00 /$ US $\$ 435.00$

Online-only institutional rate: $£ 199.00 / U S \$ 367.00$

For special $\mathrm{IOM}^{3}$ member rates please email

subscriptions@maney.co.uk

\section{For further information or to subscribe online please visit www.maney.co.uk}



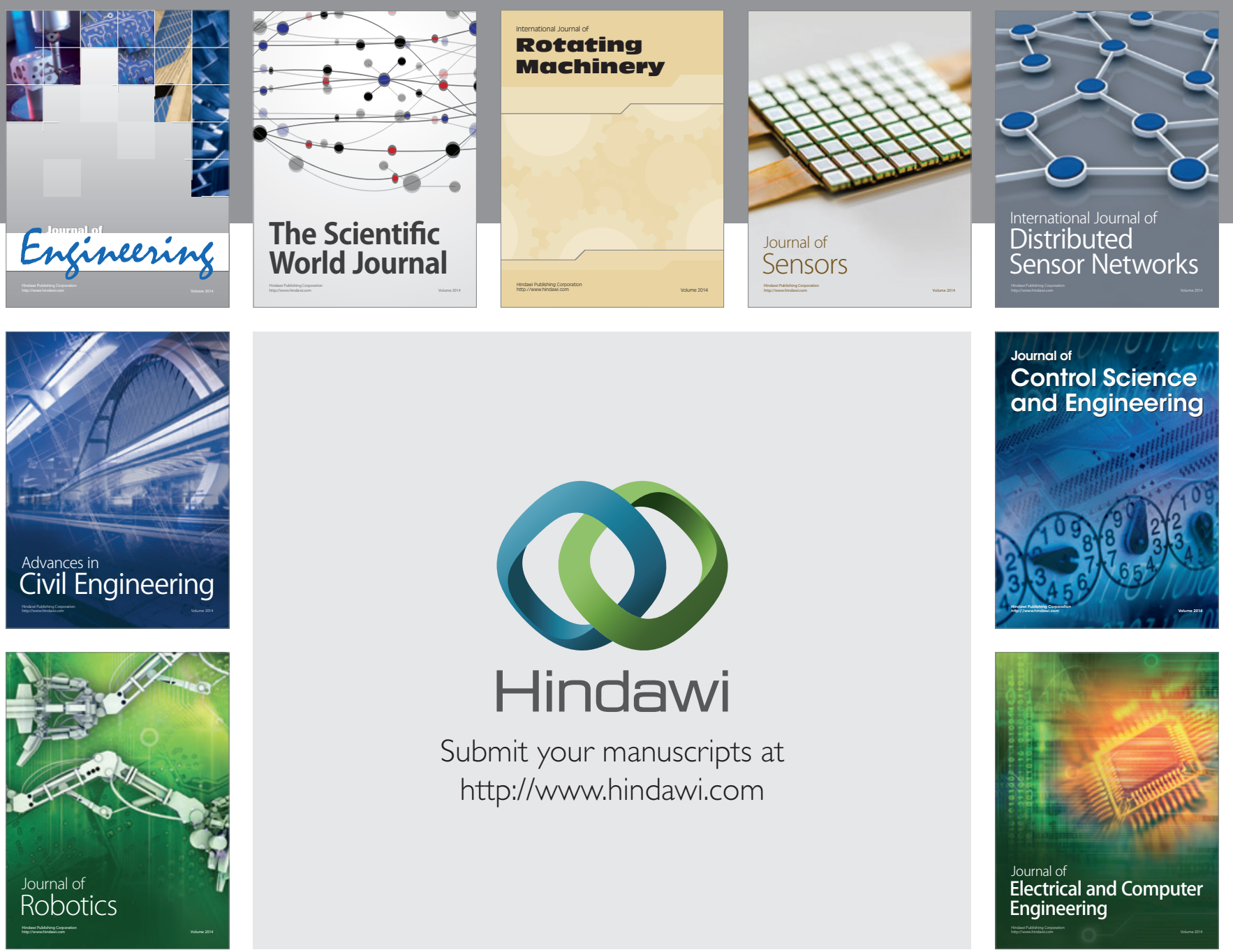

Submit your manuscripts at

http://www.hindawi.com
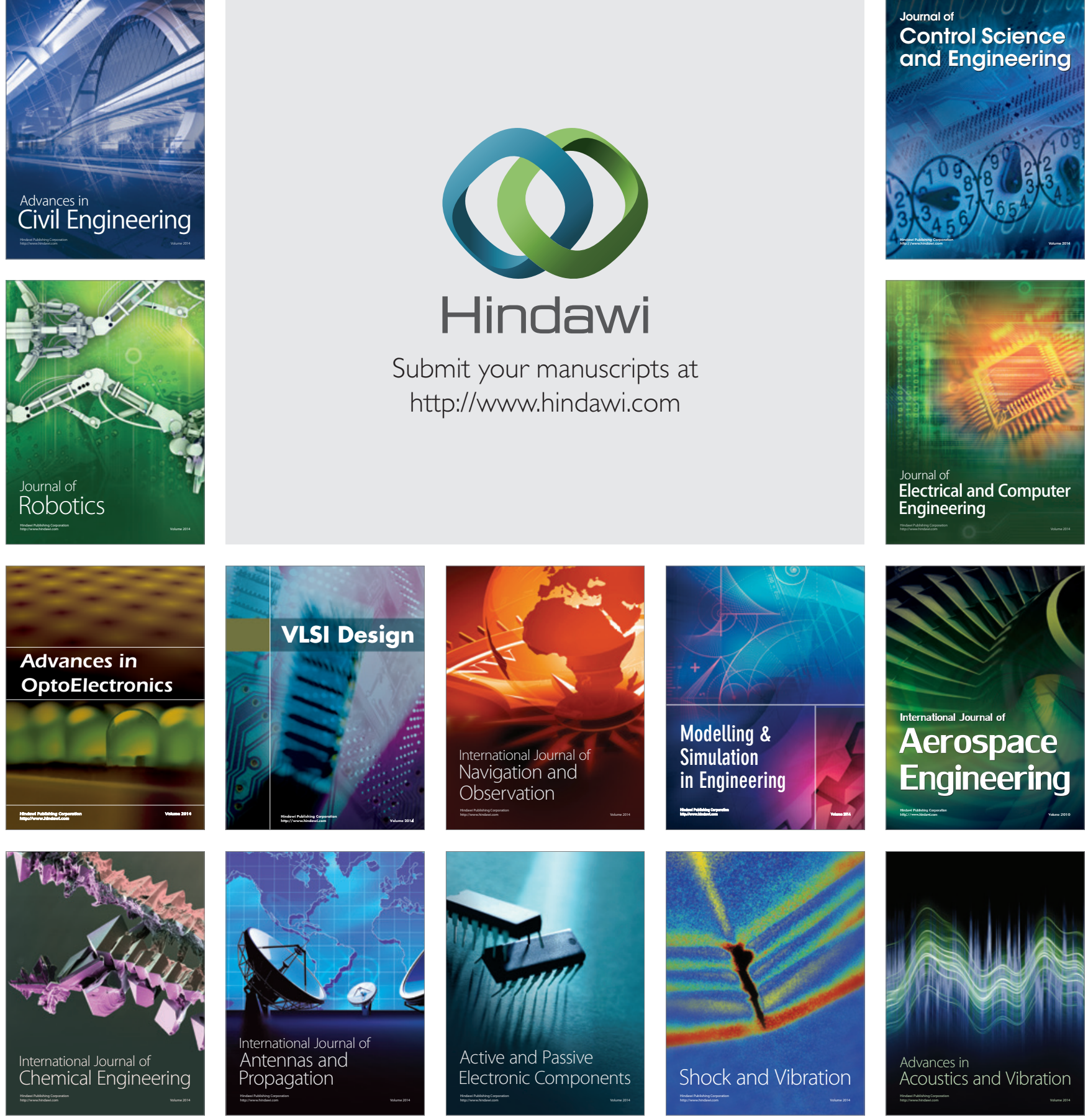